\title{
Screening and evaluation of newly diagnosed cardiovascular diseases in first-trimester asymptomatic pregnant women in a tertiary antenatal care center in Turkey
}

\author{
(D) Veciha Özlem Bozkaya*, (1) Zeynep Aslı Oskovi Kaplan**, (1) Emre Özgü**, () Yaprak Engin-Üstün** \\ Departments of *Cardiology, and **0bstetric and Gynecology, Zekai Tahir Burak Women's \\ Health Training and Research Hospital; Ankara-Turkey
}

\section{ABSTRACT}

Objective: Cardiovascular disease (CVD) is the leading cause of death during pregnancy. Therefore, its detection early in pregnancy is of great importance. In this study, we aimed to investigate the rate and spectrum of CVD among healthy women in the first trimester of pregnancy.

Methods: A total of 900 women in the first trimester of pregnancy, who attended the antenatal outpatient clinic of a tertiary care center in Anka$\mathrm{ra}$, Turkey, for a routine pregnancy examination, were recruited into this prospective study. Patients with a history of chronic systemic diseases, CVD, and/or a family history of an early onset CVD, and multiple pregnancies were excluded. Patients who were included in the study underwent electrocardiography and transthoracic echocardiography by the same cardiologist.

Results: The rate of newly diagnosed CVD cases among asymptomatic pregnant women without any cardiac or clinical risk factors was $5.2 \%$ $(n=47)$. The following CVDs were detected: rheumatic heart disease $(n=26 ; 55.3 \%)$, congenital heart disease $(n=13 ; 27.6 \%)$, and isolated valve disease (moderate and severe) $(n=8 ; 17 \%)$. The mitral valve prolapse was detected in 32 women $(3.5 \%)$ and atrial septal aneurysm in 51 women $(5.67 \%)$. Thirty women $(3.3 \%)$ had arrhythmia.

Conclusion: The CVD rate of $5.2 \%$ among healthy women in the first trimester of pregnancy shows that the clinicians must keep in mind that during pregnancy, physiological changes in the cardiovascular system may aggravate an undiagnosed disease, and they should be alert even in case of mild cardiac symptoms that may interfere with pregnancy complaints. (Anatol J Cardiol 2020; 23: 99-104)

Keywords: cardiovascular diseases, pregnancy, echocardiography, diagnosis, local medical data

\section{Introduction}

Cardiovascular disease (CVD) is the leading cause of death during pregnancy in developed countries, and cardiovascular complications may develop in $0.2 \%-4 \%$ of pregnancies, even if no prior cardiac disease is known (1,2). The rate of CVD in pregnant women is rising, primarily due to an increased number of women with congenital heart disease (CHD) reaching childbearing age and the alterations in demographics associated with advancing maternal age (3). As specified in the European Society of Cardiology (ESC) and American College of Cardiology/ American Heart Association (ACC/AHA) guidelines, the spectrum of CVD among pregnant woman changes among countries (4). In the Western world, CHD is the most common CVD during the pregnancy $(75 \%-82 \%)$, whereas in non-Western coun- tries, rheumatic heart disease (RHD) is the most common CVD $(56 \%-89 \%)$ (2). Transthoracic echocardiography (TTE) is most commonly used in diagnosing CVD.

Major changes happen in the cardiovascular system during pregnancy. The blood volume increases up to $50 \%$, the heart rate increases for approximately $20 \%$, the stroke volume increases for approximately $30 \%$, and cardiac output increases for approximately $50 \%$ when compared to non-pregnant levels (5). A routine cardiac screening during pregnancy is not recommended in the guidelines; however, an early diagnosis of CVD is important to decrease maternal morbidity and mortality. In pregnant women, routine complaints such as dyspnea, palpitation, and loss in the effort capacity can mimic heart diseases, so it may be difficult to suspect a CVD during pregnancy (6). Therefore, a cardiovascular risk assessment at the beginning of pregnancy gains importance.

Address for correspondence: Dr. Veciha Özlem Bozkaya, Zekai Tahir Burak Kadın Sağlığı Eğitim ve Araştırma Hastanesi, 
To the best of our knowledge, no study has been published yet in Turkey on cardiac scan in healthy pregnant women. In the present study, by performing routine cardiac screening among pregnant women in the first trimester, we aimed to diagnose CVD and analyze a CVD spectrum among first-trimester healthy pregnant women who visited the antenatal outpatient clinics for routine examination. This study would help to determine the prevalence and distribution of CVD and its potential risks among asymptomatic pregnant women, and it may shed some light on the potential risks of cardiac diseases during antenatal care, to take precautions during the follow-up to protect the mother and the fetus.

\section{Methods}

This cross-sectional study was conducted between March 2017 and March 2018, in a high-capacity tertiary delivery center with 17.000 deliveries per year (Zekai Tahir Burak Women's Health Training and Research Hospital, Ankara, Turkey). During the planned study period, we enrolled 900 pregnant women who were in the first trimester and visited the antenatal outpatient clinic for a routine pregnancy examination. Written and verbal consents were obtained from all patients. The study protocol was approved by the Local Institutional Review Board (protocol number 15/2017, Ethical Committee Number 542019). All patients' medical history and demographic features were recorded upon the first admission.

Pregnant women aged $>18$ years who had no cardiac symptoms and who were in the first trimester of their pregnancy were included in the study. Patients with a history of chronic systemic disease (such as hypertension, diabetes, thyroid diseases, rheumatic diseases, etc.), CVD and/or a family history of early onset CVD, and multiple pregnancies were excluded from the study. Cases with high-risk pregnancy were additionally excluded from the study. All patients underwent routine cardiac examination by a single trained cardiologist. Pregnant women with cardiac abnormalities or symptoms such as chest pain, shortness of breath and palpitation or with cardiac auscultation findings were not included. The age, body mass index (BMI), and systolic and diastolic blood pressure of all pregnant women were recorded. BMI was calculated as weight/height ${ }^{2}$ $\left(\mathrm{kg} / \mathrm{m}^{2}\right)$. A 12-lead echocardiography (ECG) (AT-102, Schiller AG, Switzerland) was recorded for each pregnant woman at rest while in the supine position. Recordings were acquired at a paper speed of $25 \mathrm{~mm} / \mathrm{s}$, with a $1 \mathrm{mV} / \mathrm{cm}$ standardization. Pregnant women with arrhythmias that were clinically important were excluded from the study.

The TTE (Vivid S5 System, GE Health-care, USA) was performed and following data were recorded: left ventricle enddiastolic diameter, left ventricle end-systolic diameter, left ventricular ejection fraction, right atrium diameter, right ventricle end-diastolic diameter, left atrium end-diastolic diameter, mitral E-wave velocity $(\mathrm{cm} / \mathrm{s})$, mitral A-wave velocity $(\mathrm{cm} / \mathrm{s})$, tricuspid annular plane systolic excursion, isovolumic relaxation time, and isovolumic contraction time. Left ventricular dimensions were determined using two-dimensional directed M-Mode ECG in the long axis of the parasternal view. The systolic function was assessed by the left ventricular ejection fraction according to the Teicholz formula. Left ventricular diastolic function was evaluated by transmitral Doppler using the pulsed-Doppler technique with two-dimensional guidance in the apical four-chamber view. Valve diseases were detected using the Doppler ECG and were classified as mild, moderate, or severe according to the ESC recommendations (7). All ECG recordings were analyzed according to the American Society of Echocardiography Convention guidelines (8). Criteria by the World Heart Federation were used for echocardiographic diagnosis of RHD (9). Valvular pathologies except RHD were classified as isolated valve diseases. Patients with non-rheumatic moderate or severe valve disease were classified as the structural heart disease group. Atrial septal aneurysm (ASA) was defined as the protrusion of interatrial septum into the left or right atrium $>15 \mathrm{~mm}$, and if the diameter of the base of aneurysm was $\geq 15 \mathrm{~mm}$ (10). Mitral valve prolapse (MVP) was defined as a displacement of the leaflet superior into the left atrium past the mitral annular plane (11).

\section{Statistical analysis}

A statistical analysis was performed using the SPSS version 22 (Statistical Package for the Social Sciences) for Windows (SPSS Inc., Chicago, IL, USA). Descriptive statistics were used for patient characteristics, ECG parameters, and detected CVD rate calculation. The lower confidence bound and upper confidence bound for observed proportions were calculated by the Wilson method for a confidence level of $95 \%$.

The sample size was estimated by power analysis based on the CVD proportions given in the ESC guidelines (12). With a post-hoc two sided power analysis for a constant proportion of 0.04 and the effect size of 0.02 with an error probability of 0.05 , the achieved power was calculated as 0.78 , which is very close to the conventional cut-off value 0.8 .

\section{Results}

For the 900 women who participated in the study, the mean weight was $65.8( \pm 12.6) \mathrm{kg}$, the mean BMI was $25.3( \pm 4.7) \mathrm{kg} /$ $\mathrm{m}^{2}$, the mean age was $27.4( \pm 5.8)$ years, the mean systolic blood pressure was $108.8( \pm 10.8)$, and diastolic blood pressure was $67.3( \pm 8.1) \mathrm{mm} \mathrm{Hg}$. On ECG, cardiac rhythms of all the women were in the sinus rhythm, and the mean the heart rate was 79 $( \pm 11) \mathrm{bpm}$. The right bundle branch block (RBBB) was detected in 14 patients on ECG. Arrhythmia was found in 30 patients $(3.3 \%)$, isolated premature ventricular complex was detected in 24 patients $(2.7 \%)$, and isolated premature atrial complex was 
detected in 6 patients $(0.6 \%)$. When the ECG findings of patients with clinically insignificant ECG anomalies were analyzed, 4 patients had both the RBBB and mild mitral regurgitation. MVP was the most common structural valvular abnormality found by TTE (32 patients, 3.56\%). ECG parameters detected in first-trimester pregnant women are listed in Table 1.

In the study, a newly diagnosed CVD rate in asymptomatic pregnant women was $5.2 \%$ ( $n=47 ; 95 \%$ confidence interval, 0.039-0.069) (Table 2). Among 47 women diagnosed with CVD, the classification of diseases was as follows: RHD ( $n=26,55.3 \%)$; CHD ( $n=13,27.6 \%)$; and isolated valve disease (moderate and severe) $(n=8,17 \%)$. Mild valve pathologies were not included in the CVD group because of their commonness and their possible physiological nature. All cardiovascular abnormalities detected by TTE are listed in Table 3. Isolated valve pathologies (nonrheumatic) were recorded in 325 patients $(36.1 \%)$, and these are listed in Table 4. Six patients had structural valve abnormalities as the myxomatous mitral valve, loose anterior mitral valve, and extremely elongated chorda tendinea. ASA, which was not defined as a CHD, was detected in 51 patients $(5.7 \%)$. The atrial septal defect (ASD) was the most common congenital anomaly $(n=8 ; 0.88 \%)$.

Table 1. Echocardiographic characteristics detected in pregnant women

\begin{tabular}{|c|c|}
\hline Characteristics & Mean $\pm S D$ (Minimum-Maximum) \\
\hline $\operatorname{LVEF}(\%)$ & $67.8 \pm 2.1(60-75 \%)$ \\
\hline $\mathrm{E}(\mathrm{cm} / \mathrm{s})$ & $0.98 \pm 0.13(0.5-1.8)$ \\
\hline$A(\mathrm{~cm} / \mathrm{s})$ & $0.76 \pm 0.12(0.4-1.6)$ \\
\hline $\mathrm{E}^{\prime}(\mathrm{cm} / \mathrm{s})$ & $13.3 \pm 2.12(6-20)$ \\
\hline$A^{\prime}(\mathrm{cm} / \mathrm{s})$ & $9.5 \pm 2.29(4-21)$ \\
\hline DT (ms) & $189.7 \pm 46.5(50-300)$ \\
\hline IVRT (ms) & $77.8 \pm 15.5(35-160)$ \\
\hline IVCT (ms) & $56.3 \pm 15.2(40-120)$ \\
\hline LVESD (cm) & $2.84 \pm 0.33(2-4.3)$ \\
\hline LVEDD (cm) & $4.34 \pm 0.27(3.4-5.1)$ \\
\hline RAEDD (cm) & $2.91 \pm 0.33(2-4)$ \\
\hline RVEDD (cm) & $2.10 \pm 0.21(1.5-3.3)$ \\
\hline LAEDD (cm) & $2.87 \pm 0.33(2-5.1)$ \\
\hline TAPSE (cm) & $2.21 \pm 0.26(1.5-2.9)$ \\
\hline LVPWd (cm) & $0.84 \pm 0.10(0.64-1.07)$ \\
\hline IVSd (cm) & $0.87 \pm 0.10(0.65-1.09)$ \\
\hline \multicolumn{2}{|c|}{$\begin{array}{l}\text { LVEF - left ventricular ejection fraction, } \mathrm{m} / \mathrm{s} \text { - mitral E-wave velocity, } \mathrm{m} / \mathrm{s} \text { - mitral } \\
\text { A-wave velocity, DT - deceleration time, IVRT - isovolumic relaxation time, } \\
\text { IVCT - isovolumic contraction time, LVEDD - left ventricle end-diastolic diameter, } \\
\text { LVESD, \% - left ventricle end-systolic diameter, RAEDD - right atrium end-diastolic } \\
\text { diameter, RVEDD - right ventricle end-diastolic diameter, LAEDD - left atrium end- } \\
\text { diastolic diameter, TAPSE - tricuspid annular plane systolic excursion, LVPWd - left } \\
\text { ventricle posterior wall thickness in diastole, IVSd - inter ventricular septum wall } \\
\text { thickness in diastole }\end{array}$} \\
\hline
\end{tabular}

Table 2. Distribution of cardiovascular disease

\begin{tabular}{|lc|}
\hline Cardiovascular disease & $\mathbf{n / 4 7}(\%)$ \\
\hline Congenital heart disease & $13(27.66 \%)$ \\
Rheumatic heart disease & $26(55.32 \%)$ \\
Mild MR & $20(42.55 \%)$ \\
Moderate MR & $4(8.51 \%)$ \\
Mild MS & $2(4.26 \%)$ \\
Isolated valve disease & $8(17.02 \%)$ \\
Moderate PS & $1(2.13 \%)$ \\
Moderate AR & $1(2.13 \%)$ \\
Moderate MR & $5(10.64 \%)$ \\
Severe MR & $1(2.13 \%)$ \\
\hline
\end{tabular}

PS - pulmonary stenosis, AR - aortic regurgitation, MR - mitral regurgitation

\section{Discussion}

In this study, we determined by TTE the rate of newly diagnosed CVD cases among healthy first-trimester asymptomatic pregnant women who applied for routine prenatal care as $5.2 \%$. To the best of our knowledge, no studies on cardiac scan in healthy first-trimester asymptomatic pregnant women have been published in Turkey.

CVD is the leading cause of maternal death worldwide (13). Dyspnea and limitation in the effort capacity are common complaints of pregnant women, which might mimic heart diseases. Most of pregnant women with undiagnosed CVD are often diagnosed in the third trimester, when the symptoms worsen. An early diagnosis of CVD is important in pregnant women to provide appropriate health care and take precautions before the symptoms get worse until delivery. With an early diagnosis, maternal mortality and morbidity may be reduced. However, there is no standard advised algorithm for routine cardiac screening to diagnose CVD earlier in pregnant women. The California Pregnancy-Associated Maternal Morbidity and Mortality Committee Cardiovascular Disease in Pregnancy and Postpartum Task Force was changed by developing a toolkit that included an overview of clinical assessment and management strategies based on risk factors, presentation signs and symptoms, vital sign abnormalities, and physical examination findings (14). In this Task Force, a cardiac screening in pregnant women with high clinical risk factors to diagnose CVD is advised. However, our study protocol included asymptomatic pregnant women without any cardiac risk or clinical and vital abnormalities, and we observed that the rate of newly diagnosed CVD was $5.2 \%$ (47/900). This rate shows that even if there are no symptoms or signs of CVD, the pregnancy can be complicated by CVD, and it is important to develop new strategies to determine maternal risk factors, which may be associated with clinical or subclinical CVD at the beginning of pregnancy. These may help us to reduce maternal/fetal morbid- 
Table 3. All cardiovascular abnormalities detected by transthoracic echocardiography

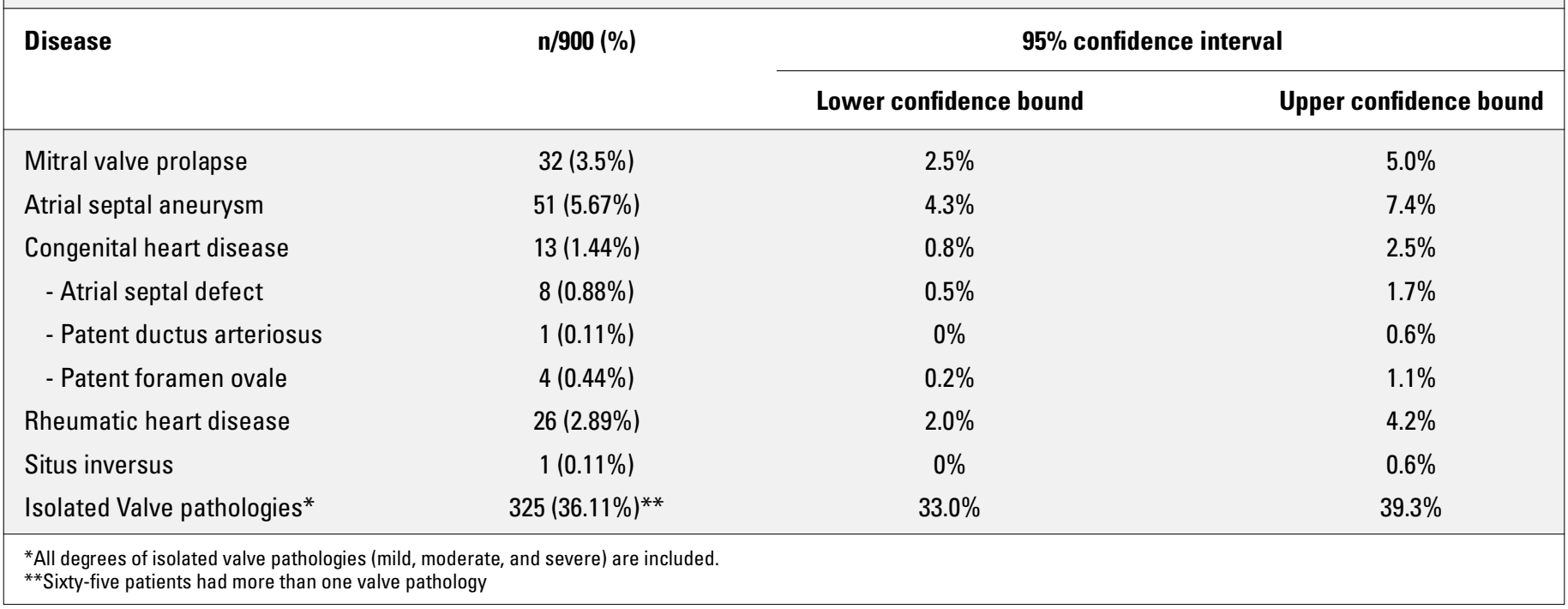

Table 4. Isolated valve pathologies

\begin{tabular}{|lccc|}
\hline Pathology & Mild & Moderate & Severe \\
\hline Aortic regurgitation & $11(1.22 \%)$ & $1(0.11 \%)$ & 0 \\
Mitral regurgitation & $73(8.11 \%)$ & $5(0.55 \%)$ & $1(0.11 \%)$ \\
Pulmonary regurgitation & $26(2.88 \%)$ & 0 & 0 \\
Pulmonary stenosis & 0 & $1(0.11 \%)$ & 0 \\
Tricuspid regurgitation & $272(30.22 \%)$ & 0 & 0 \\
\hline
\end{tabular}

ity and mortality caused by CVDs. As a result of a registry from the ESC called the Registry of Pregnancy and Cardiac Disease (ROPAC), the modified World Health Organization (mWHO) risk classification is a useful guide to predict cardiac events during pregnancy in women with CVD in developed countries, but this seems less effective in developing countries because of the difference in the CVD spectrum (15). The ROPAC included a total of 2.742 pregnant women (mean age, $29.2 \pm 5.5$ years) previously diagnosed with CVD. This study showed that the current criteria to determine the risk of CVD in pregnancy must have been modified due to patients' symptoms and characteristics. Different from these studies, our study analyzed pregnant women without a previous diagnosis, and our results show that the risk assessment of all pregnant women could be beneficial.

In a study by Subbaiah et al. (16), cardiac disease was found to complicate $3.8 \%$ of pregnancies. In this retrospective study, pregnant women were diagnosed with CVD in their third trimester. In our prospective study, 47 first-trimester pregnant women $(5.22 \%)$ among 900 subjects attended the antenatal outpatient clinic for routine examination and were diagnosed with CVD for the first time.

In the ESC guidelines, the rate of CVD in pregnant women was reported as $0.2 \%-4 \%$ (12). The distribution of CVD in pregnancy varies significantly depending on the ethnicity of the mother and influences the disease rates and prognoses. RHD is more common in developing countries, while it is rare in the Western world (17).

In a population-based retrospective study from Turkey, which analyzed the maternal deaths retrospectively in 779 women, $15.5 \%$ and $18.4 \%$ of maternal deaths stemmed from cardiac diseases in 2007 and 2008, respectively, and valvular pathologies were the leading cardiovascular pathology (18). In their study population, valvular heart disease was the leading cause of maternal death for cardiac reasons $(25.6 \%)$. A retrospective study from Turkey by Davutoğlu et al. (19) stated that the RHD rate was

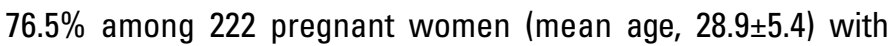
a previous CVD diagnosis. In our present investigation, among 47 patients with CVD, 26 women had RHD (55.3\%). Our results have shown that RHD is still the most common CVD in pregnant women, which is similar to data from developing countries (2), but these data may indicate that the rate of RHD seems to be declining in our country, although it is still the most common CVD among pregnant women globally.

Due to the recent developments in surgical and medical treatment of CHDs, more patients have been reaching the childbearing age, and in these circumstances, CHDs have started to be detected more frequently than RHD in developed countries (20). In our study population, the CHD rate was $27.6 \%$. ASD was the most common congenital anomaly among CHD $(n=8 / 900$; $0.88 \%)$.

We observed that, excluding CVD, the most frequent cardiac structural anomaly was ASA. The prevalence of ASA varies in literature, but TTE studies estimated the rates between $0.08 \%$ and $2.42 \%(21)$. In a large autopsy series, the prevalence of ASA was reported as $1 \%$ (22). In our study, 51 women had ASA (5.67\%). We have found a higher rate of ASA among pregnant women when compared with rates given in the literature. A study with a large patient group reported that the prevalence of ASA was 
$2.42 \%$, and it was 1.7 times higher among women (23). A higher rate observed in our study may be caused by the selection of patient group, which included only asymptomatic pregnant women. However, any other data on risk factors of ASA were not evaluated in our study.

ASA increases the risks of maternal morbidities such as atrial arrhythmias, systemic embolism, and myocardial dysfunction/ heart failure (24). It may cause clinical symptoms of dyspnea, palpitation, angina, or thromboembolic accidents (25). There are no clear guidelines, reports, or expert opinions about the management of such conditions during pregnancy. Risk factors associated with adverse maternal cardiac outcomes in pregnant women with heart disease are classified in the reports by WHO, Zwangerschap bij Aangeboren Hartafwijking (ZAHARA), and Cardiac Disease in Pregnancy (CARPREG) (25-27). However, ASA has not been classified in those reports.

Another structural cardiac anomaly is MVP, and there were $32 \operatorname{MVP}(3.56 \%)$ cases among 900 patients. This ratio was comparable to previous reports. Although rare, more serious complications of MVP, such as arrhythmia, infective endocarditis, and cerebral ischemic events, have been reported during pregnancy (28). In our study, there were no complications associated with MVP. Symptoms are variable, but the most frequent complaints are dizziness, palpitations, and weakness (29). A debate still remains on the management of MVP in pregnant patients. With a detailed analysis, the clinical importance of MVP may be determined among pregnant women. Isolated valve disease is common among pregnant women, and 105 pregnant women had isolated valve disease. Most of these cases were mitral valve pathologies.

The nine hundred pregnant women were not followed during the three trimesters and during childbirth, which can be considered a limitation to this study, and our hospital was not able to follow patients with high cardiac risk, so the patients with CVD, especially with severe valve diseases were referred to a multidisciplinary center, and no further data were received about subsequent examinations. Another limitation to our study is the involvement of a tertiary care center where women with problematic pregnancies were referred. Notwithstanding, the patients were selected randomly from the outpatient clinic in which only the first-trimester pregnant women without known risk factors about pregnancy (chronic diseases, thrombophilia, multiple pregnancy, and pregnancy after assisted reproductive techniques) were examined.

As a result of our prospective study, a newly diagnosed CVD rate among 900 healthy first-trimester asymptomatic pregnant women who attended routine prenatal care was $5.2 \%$, and RHD was still the most common reason among all CVD cases in our country $(55.3 \%)$ similar to the results in other developing countries. This substantial rate shows that even if pregnant women do not have any clinical risk or cardiac symptom, they should be referred to a cardiologist and undergo ECG in their first trimester. Thus, follow-up strategies can be improved at the beginning of pregnancy when diagnosed with CVD.

\section{Conclusion}

Cardiac screening during pregnancy may seem to be an expensive process. However, the detection of cardiac diseases during pregnancy can be lifesaving, due to the fact that CVD is the major cause of maternal death. In our study, the CVD rate of $5.2 \%$ among healthy pregnant women in the first trimester shows that the clinicians must keep in mind that during pregnancy, physiological changes in the cardiovascular system may aggravate an undiagnosed disease, and they should be alert even in the case of mild cardiac symptoms that may interfere with pregnancy complaints.

Conflict of interest: None declared.

Peer-review: Externally peer-reviewed.

Authorship contributions: Concept - V.Ö.B., Z.A.O.K., E.Ö., Y.E.Ü.; Design - V.Ö.B., Z.A.O.K., E.Ö., Y.E.Ü.; Supervision - Y.E.Ü.; Funding V.Ö.B., Z.A.O.K., E.Ö., Y.E.Ü.; Materials - E.Ö.; Data collection and/or processing - V.Ö.B.; Analysis and/or interpretation - V.Ö.B.; Literature search - V.Ö.B., Z.A.O.K., E.Ö., Y.E.Ü.; Writing - V.Ö.B., Z.A.O.K.; Critical review - V.Ö.B., Z.A.O.K.

\section{References}

1. Adam K. Pregnancy in Women with Cardiovascular Diseases. Methodist Debakey Cardiovasc J 2017; 13: 209-15.

2. Bouvier-Colle $M H$, Mohangoo AD, Gissler M, Novak-Antolic Z, Vutuc C, Szamotulska K, et al.; Euro-Peristat Scientific Committee. What about the mothers? An analysis of maternal mortality and morbidity in perinatal health surveillance systems in Europe. BJOG 2012; 119: 880-9. [CrossRef]

3. D'Souza R, Sermer M, Silversides CK. Pregnancy in women with congenital heart disease. Obstet Med 2015; 8: 18-25. [CrossRef]

4. Ashrafi R, Curtis SL. Heart Disease and Pregnancy. Cardiol Ther 2017; 6: 157-73. [CrossRef]

5. Troiano NH. Physiologic and Hemodynamic Changes During Pregnancy. AACN Adv Crit Care 2018; 29: 273-83. [CrossRef]

6. Regitz-Zagrosek V, Seeland U, Geibel-Zehender A, Gohlke-Bärwolf C, Kruck I, Schaefer C. Cardiovascular diseases in pregnancy. Dtsch Arztebl Int 2011; 108: 267-73. [CrossRef]

7. Vahanian A, Baumgartner H, Bax J, Butchart E, Dion R, Filippatos G, et al.; Task Force on the Management of Valvular Hearth Disease of the European Society of Cardiology; ESC Committee for Practice Guidelines. Guidelines on the management of valvular heart disease: The Task Force on the Management of Valvular Heart Disease of the European Society of Cardiology. Eur Heart J 2007; 28: 230-68.

8. Sahn DJ, DeMaria A, Kisslo J, Weyman A. Recommendations regarding quantitation in $\mathrm{M}$-mode echocardiography: results of a survey of echocardiographic measurements. Circulation 1978; 58: 1072-83. [CrossRef]

9. Reményi B, Wilson N, Steer A, Ferreira B, Kado J, Kumar K, et al. World Heart Federation criteria for echocardiographic diagnosis of rheumatic heart disease--an evidence-based guideline. Nat Rev Cardiol 2012; 9: 297-309. [CrossRef] 
10. Hanley PC, Tajik AJ, Hynes JK, Edwards WD, Reeder GS, Hagler DJ, et al. Diagnosis and classification of atrial septal aneurysm by twodimensional echocardiography: report of 80 consecutive cases. J Am Coll Cardiol 1985; 6: 1370-82. [CrossRef]

11. Shah PM. Current concepts in mitral valve prolapse--diagnosis and management. J Cardiol 2010; 56: 125-33. [CrossRef]

12. Seeland U, Bauersachs J, Roos-Hesselink J, Regitz-Zagrosek V. Update of the ESC guidelines 2018 on cardiovascular diseases during pregnancy: Most important facts. Herz 2018; 43: 710-8. [CrossRef]

13. Sliwa K, Böhm M. Incidence and prevalence of pregnancy-related heart disease. Cardiovasc Res 2014; 101: 554-60. [CrossRef]

14. Hameed AB, Lawton ES, McCain CL, Morton CH, Mitchell C, Main EK, et al. Pregnancy-related cardiovascular deaths in California: beyond peripartum cardiomyopathy. Am J Obstet Gynecol 2015; 213: 379. [CrossRef]

15. van Hagen IM, Boersma $E$, Johnson MR, Thorne SA, Parsonage WA, Escribano Subías P, et al.; ROPAC investigators and EORP team. Global cardiac risk assessment in the Registry Of Pregnancy And Cardiac disease: results of a registry from the European Society of Cardiology. Eur J Heart Fail 2016; 18: 523-33. [CrossRef]

16. Subbaiah M, Sharma V, Kumar S, Rajeshwari S, Kothari SS, Roy KK, et al. Heart disease in pregnancy: cardiac and obstetric outcomes. Arch Gynecol Obstet 2013; 288: 23-7. [CrossRef]

17. Seckeler MD, Hoke TR. The worldwide epidemiology of acute rheumatic fever and rheumatic heart disease. Clin Epidemiol 2011; 3: 67-84. [CrossRef]

18. Engin-Üstün $Y$, Çelen Ş, Özcan A, Sanisoğlu S, Karaahmetoğlu S, Gül $\mathrm{R}$, et al. Maternal mortality from cardiac disease in Turkey: a population-based study. J Matern Fetal Neonatal Med 2012; 25: 2451-3.

19. Davutoğlu E, Yüksel MA, Öncül M, Çebi Ş, Madazli R. Heart Disease and Pregnancy; Maternal and Fetal Outcomes. Turkiye Klinikleri J Gynecol Obst 2015; 25: 103-10. [CrossRef]
20. Gill HK, Splitt M, Sharland GK, Simpson JM. Patterns of recurrence of congenital heart disease: an analysis of 6,640 consecutive pregnancies evaluated by detailed fetal echocardiography. J Am Coll Cardiol 2003; 42: 923-9. [CrossRef]

21. Katayama H, Mitamura H, Mitani K, Nakagawa S, Ui S, Kimura M. Incidence of atrial septal aneurysm: echocardiographic and pathologic analysis. J Cardiol 1990; 20: 411-21.

22. Silver MD, Dorsey JS. Aneurysms of the septum primum in adults. Arch Pathol Lab Med 1978; 102: 62-5.

23. Jatav RK, Kumbhare MB, Surender T, Rachan Ch, Krishna TVV. Atrial septal aneurysm in adult patients: spectrum of clinical, echocardiographic presentation and to propose a new classification on the basis of transthoracic-two-dimensional echocardiography. Int J Res Med Sci 2014; 2: 708-17. [CrossRef]

24. Altraigey A, Mosad A, Tawfik W. Atrial Septal Aneurysm during Pregnancy: A Case Report. Austin J Obstet Gynecol 2018; 5: 1119.

25. Chen Y, Mou Y, Jiang LJ, Hu SJ. Congenital giant left atrial appendage aneurysm: a case report. J Cardiothorac Surg 2017; 12: 15.

26. Silversides CK, Grewal J, Mason J, Sermer M, Kiess M, Rychel V, et al. Pregnancy Outcomes in Women With Heart Disease: The CARPREG II Study. J Am Coll Cardiol 2018; 71: 2419-30. [CrossRef]

27. Suwanrath $C$, Thongphanang P, Pinjaroen S, Suwanugsorn S. Validation of modified World Health Organization classification for pregnant women with heart disease in a tertiary care center in southern Thailand. Int J Womens Health 2018; 10: 47-53. [CrossRef]

28. Chia YT, Yeoh SC, Lim MC, Viegas OA, Ratnam SS. Pregnancy outcome and mitral valve prolapse. Asia Oceania J Obstet Gynaecol 1994; 20: 383-8. [CrossRef]

29. Kucharczyk-Petryka E, Mamcarz A, Braksator W, Sawicki W, Dłuzniewski M. Mitral valve prolapse at pregnancy-is it a real clinical problem?. Pol Arch Med Wewn 2005; 114: 1084-8. 